obtained from the large gland where there was no pus, and from the skin. On inoculation, the small cocci were found to be non-pathogenic to a guinea-pig and to a pig. From the mesenteric glands of this case organisms belonging to the colon group, producing acid and gas on some sugar media, were obtained. The pasteurella-like organism was not obtained directly from the lesions. A guinea-pig was inoculated with loops of fluid from the large gland where there was no pus. It died in a fortnight, and showed the presence of an abscess the size of a walnut at the site of inoculation, but no other post-mortem lesions. Cultures made from the abscess were overgrown by Gram-positive cocci, some white and some golden, and on replating only these organisms were obtained. Smears from the inguinal region showed the presence of small bipolar bacilli from the abscess; these small bipolar Gram-negative bacilli were numerous. There were also larger Gram-negative bacilli and Grampositive cocci. Smears from the liver and heart-blood showed nothing.

The interest of these cases lies in the isolation from one of them of an organism apparently related to, though in some important particulars different from, the pasteurella group of bacteria. In the other case, though this organism was not isolated, it was apparently detected in smears from the organs of the infected pig, and in smears from the organs of the guinea-pig inoculated with material from this pig. The chief point of difference between the organism isolated and the pasteurella group consists in its more abundant growth on agar, and in the fact that it produces an extensive necrotic area at the site of inoculation in rabbits. Its morphology and sugar reactions link it up with the pasteurella group. The latter results, on the five sugars tested, agree absolutely with our laboratory strains of rabbit pasteurella (three sources), pig pasteurella (Kral), cat pasteurella, rat pasteurella, one isolated from a contaminated pleuro-virus, and a New South Wales pig pasteurella. Of sixteen strains of bacillus pestis isolated from various sources (human, rats, marsupial) during the last ten years, all gave acid on glucose, one gave acid in saccharose after eight days, and two--of great interest, as apparently representing a mutational change of the organism in a small epidemic -gave acid in mannite. Considerable difficulty was experienced in working at these cases owing to a marked degree of secondary and putrefactive infection being also present.

\title{
THE EFFECT OF NUCLEIN ON THE BLOOD.
}

By B. F. KAUPP, M.S., D.V.S., Professor of Pathology, Div. Vet. Sci., Colo. State College, and Pathologist to the Colorado Experiment Station, U.S.A.

NUCLEIN is an organic body contained within the nuclei of cells. It is acid in reaction. In composition it has been placed between proteid and nucleinic acid. It contains from 3 to ro per cent. phosphorus. When combined with albumen it is sometimes spoken of as a nucleo-proteid. Physically it is an amorphous substance. On boiling with alkalies phosphoric acid is set free. After the isolation 
of the nuclein from albuminous material, with which it is associated, by artificial digestion of the proteid, the nuclein is brought into solution by potassium hydroxide. The nucleinic acids of all nucleins are the same, but the basic portions differ in the different nucleins. The basic substance, on decomposition, yields one or more of the xanthin bodies. As a rule nucleins are insoluble in dilute acids, but soluble in dilute alkalies. Vaughn states that as a result of this phase they resist peptic digestion, and by artificial digestion, on account of this resistance, may be separated from most proteid bodies. Paranuclein is said to be an antecedent of nuclein. Histologically and functionally while they appear to be nucleins, yet they do not yield xanthin bases, such as adenin, guanin, sarcin, and xanthin, as do true nucleins. When a nucleo-proteid substance is subjected to peptic digestion the albumen is converted into peptone and the nuclein forms an insoluble precipitate.

As stated above, nuclein is obtained from many sources. Meischner first studied this substance about the year I874, and gave to it the name nuclein. He obtained it from the yolk of eggs. Hoppe-Seyler was the first to prepare nuclein from yeast. Lubarin was the first to prepare nuclein from casein of milk. Plosz was the first to prepare nuclein from the blood corpuscles of birds. Commercially, nuclein is prepared either from yeast or the germ of wheat.

Vaughn has successfully used nuclein in the treatment of tuberculosis in persons.

Ferguson has successfully used nuclein in progressive anæmia.

Jacobsohn makes report of treatment of diphtheria, scarlet fever, and measles in man, and reports good results.

Excellent results have been repeatedly reported in the treatment of canine distemper.

Hiss and Zinsser report excellent results from the use in the human family of leucocyte extracts. In the general summary and discussion of their lengthy article on their experiments we find the following of interest: Leucocytes play a dominant part in the protection of the animal economy-a part which in many infections, especially those in which poisoning is supposed to depend on endotoxins, necessitates the direct intervention of the leucocytes themselves between the invading micro-organism and their poisons and the more highly specialised cells of the animal.

Animals suffering from severe septicæmias and poisonings following intravenous injections of such organisms as staphylococci, streptococci, pneumococci, and meningococci have shown beneficial results from treatment with extracts of leucocytes, and have in many instances survived infections fatal to the control animals in thirty-six hours, even when treatment has been delayed as late as twenty-four hours.

The action of the extracted substances is evidenced in many instances by the marked fall in temperature and by a conservation or rapid return to normal of the animal's weight. One carefully following the experiments, and noting the immediate effect on the temperature and the conservation and quick return to normal weight of the normal animals, must conclude that the principal substance at work is one active in neutralising poisons, and thus able to relieve the animal economy and give the phagocyting cells an opportunity 
to carry on their work of ingesting the germs, and thus permanently rendering them harmless.

Freshley found that living leucocytes when introduced into an infected animal, even intraperitoneally, are practically without effect on systemic infection. The lives of the animals are not lengthened, and these intact leucocytes seem to. have no influence on the temperatures.

The experiments conducted in this laboratory were for the purpose of determining the following points :-

First, The effect of nuclein on erythrocytes.

Second, The effect of nuclein on the hæmoglobin.

Third, The effect of nuclein on the time of coagulation.

Fourth, The effect of nuclein on the power of phagocytosis.

Fifth, The effect of nuclein on leucocytes both in quantity and differentially.

Sixth, The effect of nuclein in vitro on the power of phagocytosis.

The nuclein used in the experiments was that made from the germ of wheat. ${ }^{1}$ Each ounce of the nuclein solution contains approximately 6 grains of sodium tritico-nucleinate. The solution is standardised to a content of I milligramme of organic phosphorus to each cc. of solution.

Case II. gives a good illustration of the effects of the results on normal rabbits.

CASE II.

\begin{tabular}{|c|c|c|c|c|c|c|c|c|}
\hline Date. & R.B.C. & $W . B . C$. & 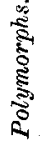 & 通 & 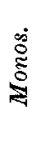 & 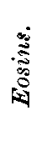 & $\frac{\dot{s}}{\mathrm{z}}$ & Remarks. \\
\hline 3.2 .11 & $6,080,000$ & 9,000 & 24 & 76 & - & 4 & 5 & No nuclein before count \\
\hline 4.2 .11 & $4,160,000$ & 8,000 & 36 & 72 & 1 & 3 & 1 & for five days. Be. \\
\hline 5.2 .11 & $6,116,000$ & 8,000 & 30 & 70 & - & 3 & 3 & ginning at 1 P.M. on \\
\hline 6.2 .11 & $6,296,000$ & 8,000 & 28 & 71 & 1 & 5 & 2 & fifth day, 1 cc. nuclein \\
\hline 7.2 .11 & $6,220,000$ & 9,000 & 22 & 78 & $\ldots$ & 4 & 2 & was given subcutane- \\
\hline 8.2 .11 & $5,556,000$ & 10,000 & 34 & 66 & 2 & 3 & 2 & ously three times a \\
\hline 9.2 .11 & $5,810,000$ & 10,000 & 30 & 69 & 1 & 5 & 1 & day, so that on the \\
\hline 10.2 .11 & $6,080,000$ & 9,000 & 44 & 55 & 1 & 4 & 1 & fifth day two injections \\
\hline 11.2 .11 & $6,720,000$ & 11,000 & 34 & 66 & \pm & 4 & 2 & were given. \\
\hline 12.2 .11 & $5,400,000$ & 11,000 & 23 & 77 & - & 2 & 1 & No more nuclein was \\
\hline 13.2 .11 & $6,200,000$ & 21,000 & 63 & 36 & 1 & 3 & 1 & given after the $15 \mathrm{th}$. \\
\hline 14.2 .11 & $5,440,000$ & 25,000 & 52 & 48 & - & 5 & - & \\
\hline 15.2.11 & $5,360,000$ & 20,000 & 38 & 61 & 1 & 2 & 1 & \\
\hline 16.2 .11 & $6,000,000$ & 15,000 & 33 & 67 & 二 & 3 & 1 & \\
\hline 17.2 .11 & $5,920,000$ & 11,000 & 26 & 74 & - & 3 & 11 & \\
\hline 18.2 .11 & $6,080,000$ & 11,000 & 34 & 65 & 1 & 1 & 1 & \\
\hline 19.2 .11 & $6,320,000$ & 10,000 & 32 & 68 & - & 4 & - & \\
\hline
\end{tabular}

From a study of this table it will be seen that there is an increase in the total number of polymorphonuclear leucocytes. No nuclein was given till noon of the fifth day. Not much change in the total number of leucocytes was noted till about the fifth day after the commencement of the administration of the nuclein. A marked increase of the polymorphonuclear leucocytes at the expense of the lymphocytes took place much earlier. With the discontinuance of 
the administration of the nuclein the total number of leucocytes soon returned to normal. This will also be noted to be true of the polymorphonuclear leucocytes. There was no effect upon the red blood cells.

Case III. was for the purpose of making a study to note the effect of nuclein on the blood in canine distemper.

The subject was a Russian wolf hound pup about four months old. He entered the hospital 22nd February r9I I.

Histo $y$-Two weeks previous he was noted to be ill. There appeared a conjunctivitis; a thin watery discharge was noted, later muco-purulent, which had a tendency to agglutinate the lids. About this time a thin watery, and later a muco-purulent, discharge was noted from the nostrils.

Symptoms.-Appetite little impaired. Great prostration. Wobbly gait. Particularly weak and wobbly in the hindquarters. First signs of corea. Very thin in flesh.

CASE III.

\begin{tabular}{|c|c|c|c|c|c|c|c|c|}
\hline Date. & R.B. $C$. & W.B.C. & 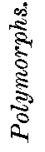 & 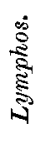 & 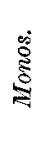 & 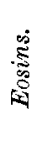 & 范 & Remarks. \\
\hline 22.2 .11 & $5,516,000$ & 7,000 & 79 & 14 & 6 & 1 & - & \multirow{21}{*}{$\begin{array}{l}\text { Count before injection of } \\
\text { nuclein. Beginning } 1 \\
\text { P.M., } 4 \text { cc. nuclein was } \\
\text { given subcutaneously } \\
\text { three times a day, so } \\
\text { that the first day only } \\
4 \text { cc. was given. } \\
\text { No nuclein was given } \\
\text { after } 7.3 .11\end{array}$} \\
\hline 23.2 .11 & $6,430,000$ & 14,000 & 82 & 13 & 2 & 1 & 2 & \\
\hline 24.2 .11 & $6,770,000$ & 14,000 & 73 & 26 & — & $\ldots$ & 1 & \\
\hline 25.2 .11 & $5,600,000$ & 16,000 & 74 & 19 & 3 & $\ldots$ & $\ldots$ & \\
\hline 26.2 .11 & $3,420,000$ & 14,000 & 73 & 23 & 3 & - & 1 & \\
\hline 27.2 .11 & $6,316,000$ & 20,000 & 74 & 33 & 1 & - & 2 & \\
\hline 28.2 .11 & $6,140,000$ & 18,000 & 67 & 25 & 4 & - & 4 & \\
\hline 1.3 .11 & $5,820,000$ & 16,000 & 71 & 26 & 1 & -- & 2 & \\
\hline 2.3 .11 & $6,142,000$ & 13,000 & 77 & 18 & 二- & 1 & 4 & \\
\hline 3.3 .11 & $5,948,000$ & 16,000 & 78 & 18 & 1 & 一 & 3 & \\
\hline 4.3 .11 & $6,000,100$ & 15,000 & 77 & 19 & 2 & 1 & 1 & \\
\hline 5.3 .11 & $6,436,000$ & 14,000 & 76 & 20 & 2 & 一 & 2 & \\
\hline 6.3 .11 & $6,628,000$ & 13,000 & 79 & 18 & 2 & 一 & 1 & \\
\hline 7.3 .11 & $6.712,000$ & 11,000 & 81 & 17 & 1 & -. & 1 & \\
\hline 8.3 .11 & $6,864,000$ & 12,000 & 85 & 14 & - & $\ldots$ & 二 & \\
\hline 0.3 .11 & $6,608,000$ & 11,000 & 81 & 16 & 1 & - & 2 & \\
\hline 10.3 .11 & $6,720,000$ & 12,000 & 72 & 36 & - & - & 2 & \\
\hline 11.3 .11 & $6,600,000$ & 13,000 & 75 & 20 & 2 & 1 & 2 & \\
\hline 12.3 .11 & $5,040,000$ & 14,000 & 77 & 30 & 3 & - & - & \\
\hline 13.3 .11 & $5,200,000$ & 10,000 & 72 & 20 & 1 & 2 & 5 & \\
\hline 14.3 .11 & $5,100,000$ & 13,000 & 75 & 19 & 3 & 1. & 2 & \\
\hline
\end{tabular}

In a summary of the above case it will be noted that a marked increase in the total number of leucocytes was observed at the end of twenty-four hours.

The nuclein was always given subcutaneously.

There was very little change in the number of polymorphonuclear leucocytes in this case.

The leucocyte content of the blood remained high after the nuclein had been discontinued eight days.

There was no change in the number of red blood cells.

This dog received no other treatment, and steadily improved from the beginning of treatment. The corea entirely disappeared.

It is conceded by the five veterinarians practising at this institution that prognosis was very unfavourable in this case, and as no 
other treatment was employed, recovery must be attributed to the nuclein.

Case IV. was a buckskin gelding, used as a cart horse about the hospital.

The object of this experiment was to determine the effect on the leucocytes, hæmoglobin, time of coagulation, and power of phagocytosis.

In using the hæmatocrit in some additional experiments not here recorded (on Case III), it was found that the blood coagulated in the tube before centrifugalisation could be accomplished. Following this observation the time of coagulation was taken, and found to be twenty seconds. At this time nuclein had been administered to this $\operatorname{dog}$ hypodermically for about ten days. After reflecting over the problem, and being aware of the statements made in different publications that an increase of certain salts or proteid substances increases the power of coagulation of the blood, it was reasoned that if the blood could be altered by the injection of nuclein subcutaneously so that the time of coagulation was materially decreased, could not this fact be taken advantage of in cases of hæmorrhage following operation or injury in which seepage persisted by injecting nuclein directly into the blood? It was determined to note the effect of nuclein upon the time of coagulation of the blood in Case IV.

CASE IV.

\begin{tabular}{|c|c|c|c|c|c|c|c|c|c|c|}
\hline Date. & R.B.C. & W.B.C. & 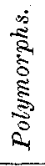 & 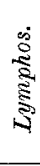 & & 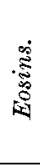 & $\stackrel{5}{3}$ & $H b$. & $\begin{array}{c}\text { Time of } \\
\text { Coag. }\end{array}$ & $\begin{array}{c}\text { Nurnber } \\
\text { of Coeci } \\
\text { per } \\
\text { Poly- } \\
\text { morph. }\end{array}$ \\
\hline 22.3 .11 & $7,100,000$ & 11,000 & 58 & 24 & 10 & 6 & 2 & 100 & $10 \mathrm{~min}$. & 10.5 \\
\hline 23.3 .11 & $6,580,000$ & 9,000 & 59 & 34 & 1 & 6 & - & 95 & 10 & $10 \cdot 3$ \\
\hline 24.3 .11 & $6,640,000$ & 11,000 & 66 & 26 & 6 & 2 & - & 100 & & $20 弓$ \\
\hline 25.3 .11 & $7,520,000$ & 12,000 & 72 & 14 & 5 & 2 & 1 & 100 & $5 \cdot 5$, & 39.9 \\
\hline 25.3 .11 & $7,680,000$ & 15,000 & 74 & 21 & - & 4 & 1 & 98 & & 25 \\
\hline 27.3 .11 & $6,942,000$ & 9,000 & 72 & 11 & 1 & 16 & & 100 & 25, & 23 \\
\hline
\end{tabular}

The count on the first day was made at I P.M. The first nuclein was given at 6 P.M. I 6 cc. was given each time hypodermically.

No nuclein was given after 6 P.M. on the 25 th.

On the $23 \mathrm{rd}, 24 \mathrm{th}$, and 25 th three injections were made.

In summarising this experiment we note that the erythrocytes remained stationary. There was a slight rise in the total number of leucocytes and in the number of polymorphonuclear leucocytes. The time of coagulation was not reduced till after twenty-four hours. After this time there was a gradual increase in the power of coagulation, till on the fifth day after the commencement of adminisstration of nuclein the blood coagulated in two and one-half minutes, against a normal time of coagulation of ten minutes. We note that the hæmoglobin content was not altered. We note that not only was there an increase in the total number of leucocytes and of polymorphonuclear leucocytes but an increase in the power of phagocytosis. 
Following the first injection of nuclein on the 25 th, it was noted that a swelling appeared in about two hours, and was more than 6 inches in diameter. We were aware that some have made the statement that severe swelling and even suppuration have followed subcutaneous injections of nuclein. This was the first swelling we had observed, and we determined, if possible, to find the cause. The laboratory assistant who administered the nuclein left the graduate measure standing upon a shelf exposed to contamination, and did not wash it before pouring out the nuclein for the following injection. Having had some experience with contamination with the bacillus. subtilis in my vaccine experiments, and being aware of the fact that a proteid substance is a good medium for germs to grow in, I became suspicious that the measure was my trouble. Afterwards the syringe and measure were boiled before each injection, with the result that there were no more swellings.

I believe that swellings following the hypodermic injections of nuclein are not due to the nuclein but to some error in technique.

Noting thus far the effect of nuclein in increasing the power of phagocytosis, we determined to make some tests to determine what effect, if any, the nuclein mixed with the serum in vitro would have upon phagocytosis. The following was one of such tests:-

\section{Case V.}

(a) W.B.C. + Plasma + B.E. $=2 \mathrm{I} \cdot 68$ cocci per cell.

(b) W.B.C. + Plasma + B.E. + Nuclein, IOO per cent. $=14.05$ cocci per cell.

(c) W.B.C. + Plasma +B.E. + Nuclein, io per cent. $=20^{\circ} 60$ cocci per cell. cell.

(d) W.B.C. + Plasma + B.E. + Nuclein, 2 per cent. $=19 \cdot 32$ cocci per

(a) was run as a control; $(b),(c),(d)$ are the tests.

It will be noted that in this experiment the nuclein had no effect on phagocytosis.

Case XII., along the same line, is of interest at this point, and is. here given.

\section{CASE XII.}

(a) W.B.C. + Plasma +B.E. $=15.40$ cocci per cell.

(b) W.B.C. + Plasma + B.E. + Nuclein I : $100=15 \cdot 62$ cocci per cell.

(c) W.B.C.+ Plasma +B.E. + Nuclein I : $200=1496$ cocci per cell.

(a) was used as a control. B.E. is abbreviation for bacillary emulsion.

The bacillary emulsion in all tests was with a twenty-four-hours' growth of streptococcus pyogenes upon glycerine agar. Emulsion made in sterilised physiological salt solution. The dilutions of nuclein were made with sterilised physiological salt solution. The technique of each is carefully checked.

As a summary of Case XII. we find an exact repetition of results as in Case V.

Case VI. was intended for the determination of the effect of 
nuclein on the blood, the nuclein being administered by the mouth. The case was a pup about five months old. A goitre was observed on the left side, which was afterwards removed and found to consist principally of a cyst.

\section{CASE VI.}

\begin{tabular}{|c|c|c|c|c|c|c|c|c|c|}
\hline Date. & R.B.C. & W.B.C. & 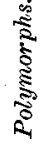 & 芯 & है & $\frac{3}{4}$ & $H b$. & $\begin{array}{l}\text { Time of } \\
\text { Coag. }\end{array}$ & $\begin{array}{c}\text { Number } \\
\text { of Cocei } \\
\text { per } \\
\text { Cell. }\end{array}$ \\
\hline 10.4 .11 & $5,860,000$ & 10,000 & 82 & 15 & - & 3 & 100 & $1.25 \mathrm{~min}$. & $13 \cdot 32$ \\
\hline 11.4 .11 & $7,060,000$ & 11,000 & 80 & 15 & 3 & 2 & 100 & 1.25 & 16.5 \\
\hline 12.4 .11 & $6,520,000$ & 5,000 & 81 & 14 & 1 & 4 & 100 & 1 & $18 \cdot 27$ \\
\hline 13.4 .11 & $6,548,000$ & 8,000 & 84 & 13 & 2 & 1 & 100 & $1 \quad "$ & 14.01 \\
\hline 14.4.11 & $6,240,000$ & 9,000 & 76 & 20 & 3 & 1 & 100 & $075 ”$ & 15 \\
\hline
\end{tabular}

$4 \mathrm{cc}$. nuclein was administered by the mouth, beginning at I P.M., 4th October I9I I. The first test was made before the administration of the nuclein. Nuclein was given three times a day before meals, so far as could be controlled. No nuclein was given after the I 3 th.

This is not considered a fair test for the leucocytes, as the experiment was not run long enough. We note the time of coagulation decreased after the second day. It may be here noted that this dog had been on an exclusive meat diet for several days before the experiment, which accounts for the short time of coagulation before administering the nuclein. We note an increase in the power of phagocytosis. The hæmoglobin and erythrocytes are unaltered.

A similar test was run in Case VII., and similar results obtained. This latter test was upon a normal horse.

As stated above, we determined to test the effects of nuclein upon the power of coagulation, the nuclein to be given intravenously. Such tests were made in Cases IX., X., and XI.

\section{CASE IX.}

The case was a grey gelding, thin in flesh, aged. Feed consisted of alfalfa hay. The solution was given intravenously (jugular vein), I oz. in $500 \mathrm{cc}$. physiological salt solution.

Time of coagulation before injection, Io minutes.

$" \quad \Rightarrow \quad 30$ minutes after injection, 7 minutes.
$" \quad$ I hour and 30 minutes after injection,
$\quad 3$ minutes.

CAse X.

Bay gelding, nine years old. Operated on. In operation large branch of circumflex was severed, and ligation seemed impossible. Severe hæmorrhage persisted after packing and suturing wound. Feed consisted of prairie hay and grain. I oz. nuclein in $500 \mathrm{cc}$. 
physiological salt solution was administered intravenously (jugular vein).

Time of coagulation before injection, 12 minutes.

Hæmorrhage" had ceased.

30 minutes after injection, 7.5 minutes.

\section{CASE XI.}

Roan mare, aged, Feed consisted of pasture grass; no dry feed. I oz. of nuclein was given in $500 \mathrm{cc}$. physiological salt solution intravenously (in jugular).

Time of coagulation before injection, ro minutes.

$" \quad$ " $\quad 30$ minutes after injections, 5 minutes.
$" \quad 4$ i hour and 30 minutes after injection,
4 minutes.
4 minutes.

These tests show that nuclein when thrown directly into the blood greatly and immediately increases the power of coagulation.

\section{CONCLUSIONS.}

As a summary of the preliminary report of investigations made in this laboratory with nuclein, the following conclusions seem justifiable:-

I. Nuclein increases the total number of leucocytes in the blood.

2. Nuclein increases the polymorphonuclear leucocytes.

3. Nuclein increases the power of phagocytosis of the individual leucocyte.

4. Nuclein has no effect upon the erythrocyte or hæmoglobin.

5. Nuclein decreases the time of coagulation of the blood, and promises to be of great value in stopping hæmorrhage in cases of wound seepage or injuries.

6. Nuclein has no effect on the power of phagocytosis in vitro.

7. To obtain the best results in cases of infectious diseases nuclein should be given hypodermically.

8. To obtain desirable results in cases of hæmorrhage the nuclein should be given intravenously. 